\title{
Correlation of Histopathological Types of Laryngeal and Nasopharyngeal Mass with PCR Detected Human Papilloma Virus -16, 18 - A Hospital Based Prospective Study
}

\author{
Dr. Oindrila Dhar ${ }^{1}$, Dr. Anjan Kumar Das ${ }^{2^{*}}$
}

3rd Year Pgt, Department of Pathology, Calcutta National Medical College and Hospital, West Bengal, India

${ }^{2}$ Professor and H.O.D., Department of Pathology, Coochbehar Government Medical College and Hospital, West Bengal, India

DOI: $10.36347 /$ sjams.2020.v08i06.013

| Received: 28.05.2020 | Accepted: 05.06.2020 | Published: 13.06.2020

*Corresponding author: Dr. Anjan Kumar Das

Abstract

Original Research Article

Introduction: Larynx is one of the most common sites of head and neck carcinoma. HPV positive oropharyngeal squamous cell carcinoma cases are gradually increasing in number. Compared to oral carcinomas, there is a greater diversity of HPV types are associated with laryngeal carcinomas. Very few studies have addressed the issue of causation regarding HPV and laryngeal carcinoma. The role of HPV in the nasopharyngeal tumours is controversial. HPV positive status is associated with a significant beneficial impact on prognosis. Materials and method: Total 53 patients from ENT department, having laryngeal or nasopharyngeal masses are included in this prospective study. During operation, part of the tissue is taken in phosphate buffer solution for detection of HPV by PCR and part of tissue is taken in formalin for histopathology. Result: Out of 35 cases of laryngeal masses, 32 patients (91.4\%) are male, 14 patients $(40 \%)$ are in $6^{\text {th }}$ decade, 22 patients $(62.86 \%)$ are smoker, 20 patients $(57.14 \%)$ presented with hoarsness of voice, 8 patients $(22.86 \%)$ have mass in both vocal cord, 21 patients $(60 \%)$ have moderately differentiated squamous cell carcinoma, $6(17.14 \%)$ have vocal cord nodule, $2(5.71 \%)$ have fibro-epithelial polyp with dysplasia, $2(5.71 \%)$ have dysplasia, $2(5,71 \%)$ have squamous cell papilloma with koilocytic changes. Remaining 2 patients have cavernous haemangioma and inverted papilloma. Out of 18 cases of nasopharyngeal masses, 14 patients $(77.78 \%)$ are male, 5 patients $(27.78 \%)$ are in $2^{\text {nd }}$ decade and 4 patients $(22.22 \%)$ are in $6^{\text {th }}$ decade, 9 patients $(50 \%)$ are smoker, 10 patients $(55.56 \%)$ presented with swelling in cervical region, fever and weight loss, 9 patients (50\%) have undifferentiated non-keratinizing nasopharyngeal carcinoma, 6 patients (33.33\%) have nasopharyngeal angiofibroma. Remaining 3 patients have keratinizing squamous cell carcinoma and non-Hodgkin lymphoma. But neither HPV-16 nor HPV-18 is found in any laryngeal or nasopharyngeal cases in this study. Conclusion: Most of the laryngeal masses are diagnosed as moderately differentiated squamous cell carcinoma and most of the nasopharyngeal masses are non-keratinizing nasopharyngeal carcinoma followed by nasopharyngeal angiofibroma. HPV-16, 18 infection may not be a leading cause of laryngeal or nasopharyngeal mass.

Keywords: PCR, HPV- 16, 18, laryngeal mass, nasopharyngeal mass.

Copyright @ 2020: This is an open-access article distributed under the terms of the Creative Commons Attribution license which permits unrestricted use, distribution, and reproduction in any medium for non-commercial use (NonCommercial, or CC-BY-NC) provided the original author and source are credited.

\section{INTRODUCTION}

In India, head and neck carcinomas accounted for $30 \%$ of all carcinomas. One of the most common sites of head and neck carcinoma is larynx. Laryngeal carcinoma is the ninth and seventh most common cause of carcinomas in males in Asia and India respectively [1]. HPV- associated cancers are well documented in cervical cancer, in which $99.7 \%$ of cases harbor a highrisk HPV type [2]. The microenvironment of the laryngeal mucosa is similar to that of the uterine cervix, which has an epithelial junctional area between squamous and columnar epithelia; the junctional area is a potential site for HPV infection [3]. Previous studies have found that low-risk HPV is associated with recurrent respiratory papillomatosis [4], however, the association between laryngeal squamous cell carcinoma (LSCC) and HPV infection remains controversial due to inconsistent results [5-7]. Like other head and neck cancers, LSCC has been clearly linked to smoking and alcohol consumption. The risk factors of LSCC are changing, as the prevalence of tobacco induced cancers has decreased and the prevalence of cancers not associated with tobacco has increased. HPV infection is a cause of squamous cancers of the oropharynx (particularly cancers of the tonsils and tongue base) [810] and emerging evidence showed that HPV infection 
may also be associated with an increased risk of LSCC [11].

While nasopharyngeal carcinoma is relatively uncommon worldwide, it is endemic in certain populations including southern China, Southeast, the Middle East, and North Africa. High-risk human papilloma virus, particularly oncogenic HPV subtypes 16, has recently been established as the primary etiologic agent in a subset of head and neck squamous cell carcinomas, the majority of which localize to the oropharynx and exhibit improved prognosis compared to patients with HPV-negative tumors [12, 13]. Given the similarities between the epithelium and lymphoid tissue of the oropharynx and nasopharynx, there has been recent interest in the potential role of HPV in NPC carcinogenesis. Though the clinical significance of HPV infection in NPC remains unclear still now.

Juvenile nasopharyngeal angiofibroma is a very rare disease. Its incidence has been cited to be $0.05 \%$ of all head and neck neoplasms as per many study reports [14]. Juvenile nasopharyngeal angiofibroma has witnessed a four-fold increase in the incidence in the current decade as compared to the 1980s. This suggests some evolving host-agentenvironmental interaction or probably a novel etiologic agent operating in this part of the world. With rising incidence of HPV- related head and neck squamous cell cancer, it is likely to affect the postnasal space. Hence the possibility of its implication in JNA cannot be ignored [15].

\section{AIMS AND OBJECTIVES}

1. To find out the different histological types of laryngeal mass

2. To find out the different histological types of nasopharyngeal mass

3. To study the association of HPV-16, 18 with different histological types of laryngeal and nasopharyngeal mass.

\section{Materials ANd Methods}

It is observational prospective hospital based study from January'18 to June'19 in the department of pathology, biochemistry and Otorhinolaryngology. Those patients, having laryngeal or nasopharyngeal mass, admitted to the Otorhinolaryngology department for the biopsy, included in this study. In operation theatre, part of the mass is taken in phosphate buffer solution for conventional PCR and another part is kept in formalin for histopathology. Tissue in phosphate buffer solution is stored in $-20^{\circ} \mathrm{C}$.

The primers to be used in the following:

1) HPV-16 -

Forward primer sequence - 5'ATA TAT GTT AGA

TTT GCA ACC AGA GAC AAC 3'

Reverse primer sequence - 5' GTC TAC GTG TGT

GCT TTG TAC GCA C3'

2) HPV-18-

Forward primer sequence - 5' CCG AGC ACG ACA GGA GAG GCT 3'

Reverse primer sequence - 5' TCG TTT TCT TCC TCT GAG TCG CTT 3'

\section{Result Analysis}

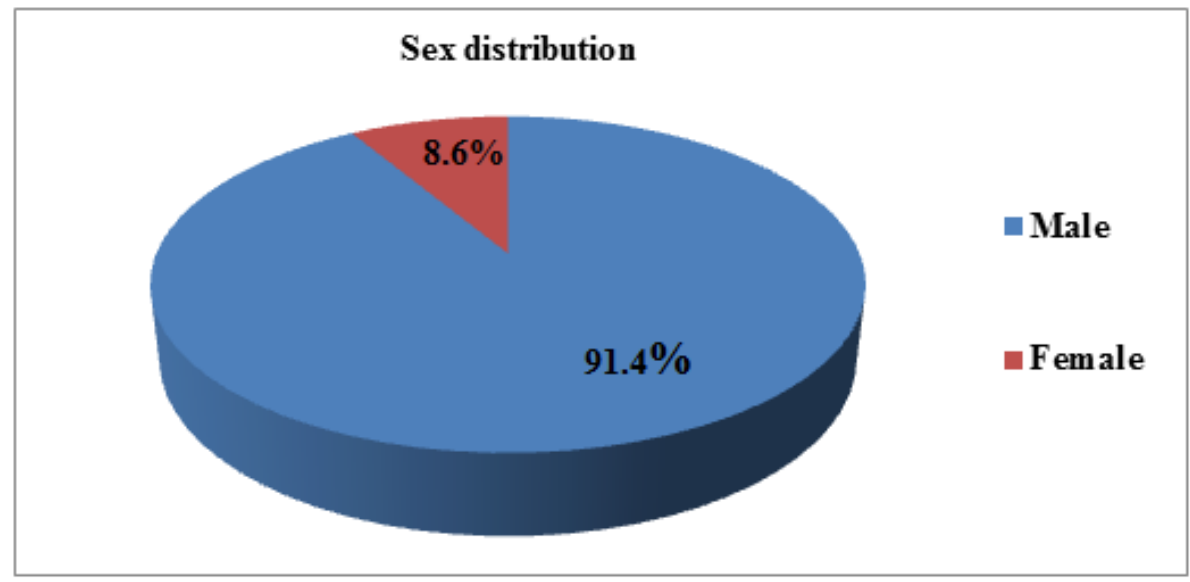

Graph-1(a): Sex distribution of the patients with laryngeal mass

Out of 35 patients with laryngeal mass, majority of the study population (91.4\%) are males.

Inference: Male preponderance is noticed. 


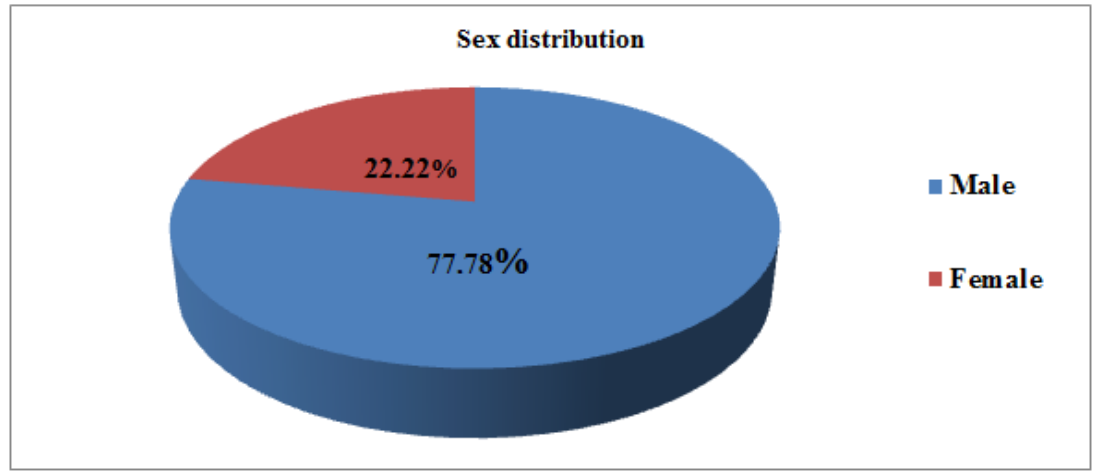

Graph-1(b): Sex distribution of the patients with nasopharyngeal mass

Out of 18 patients with nasopharyngeal mass, majority (77.78\%) are male and male to female ratio 3.5.

Inference: Male preponderance is noticed.

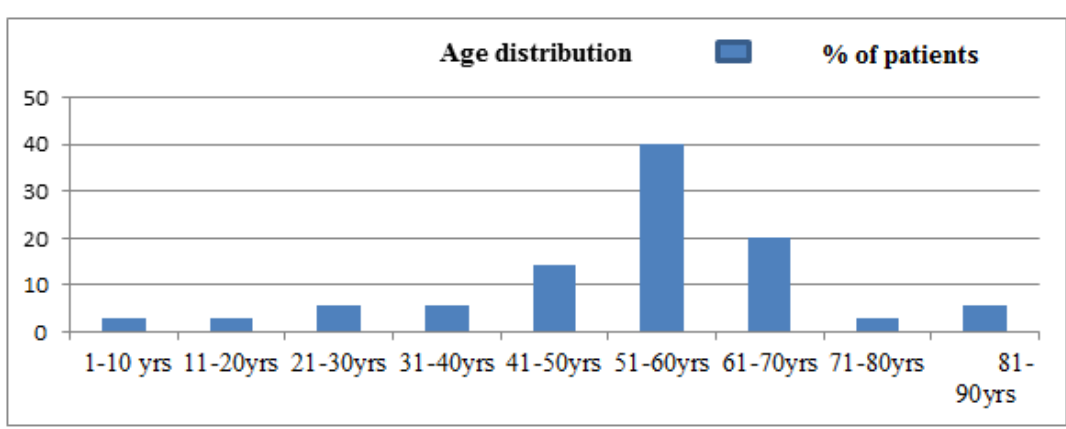

Graph-2(a): Age distribution of the patients with laryngeal mass

Inference- Majority of patients with laryngeal mass is in $6^{\text {th }}$ decade.

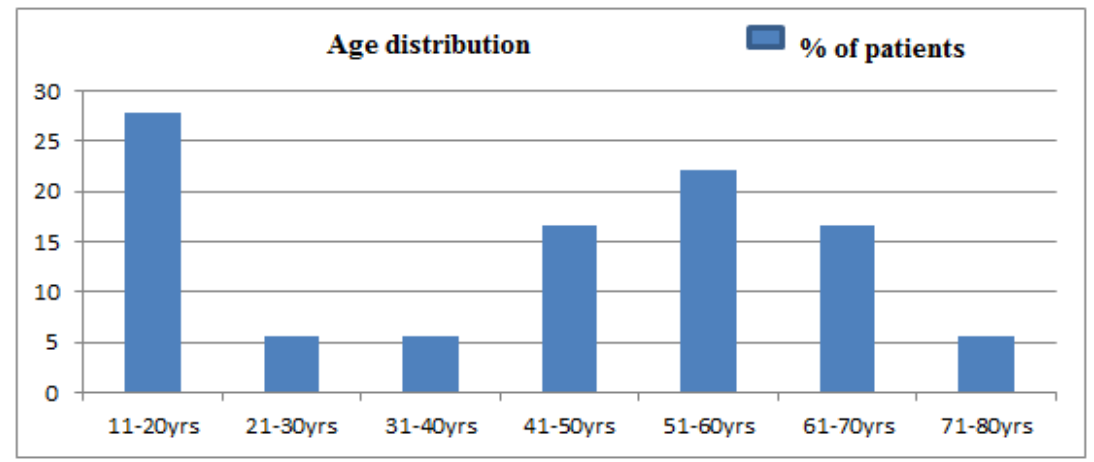

Graph-2(b): Age distribution of patients with nasopharyngeal mass

Inference- Majority of patients with the nasopharyngeal mass is in $2^{\text {nd }}$ decade, followed by $6^{\text {th }}$ decade.

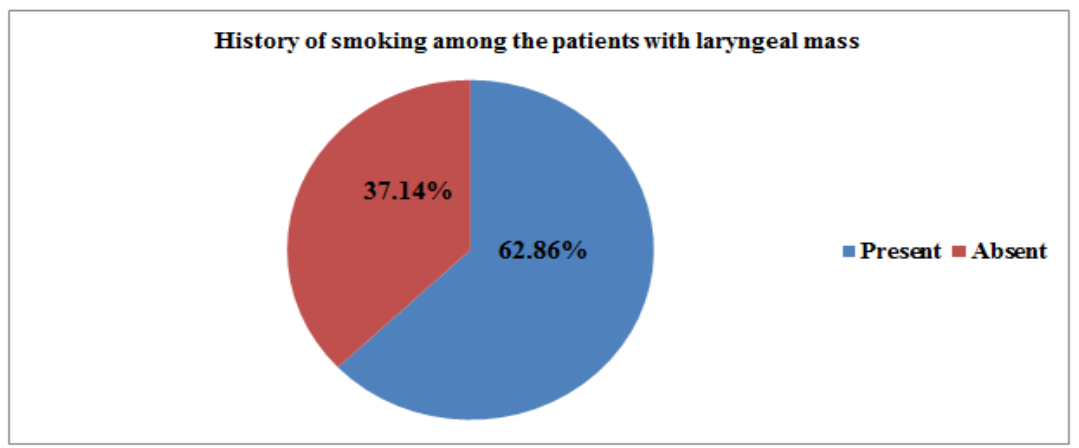

Graph-3(a): Distribution of history of smoking among patients with laryngeal mass 
Inference- Majority of the patients with laryngeal mass have positive history of smoking (62.86\%).

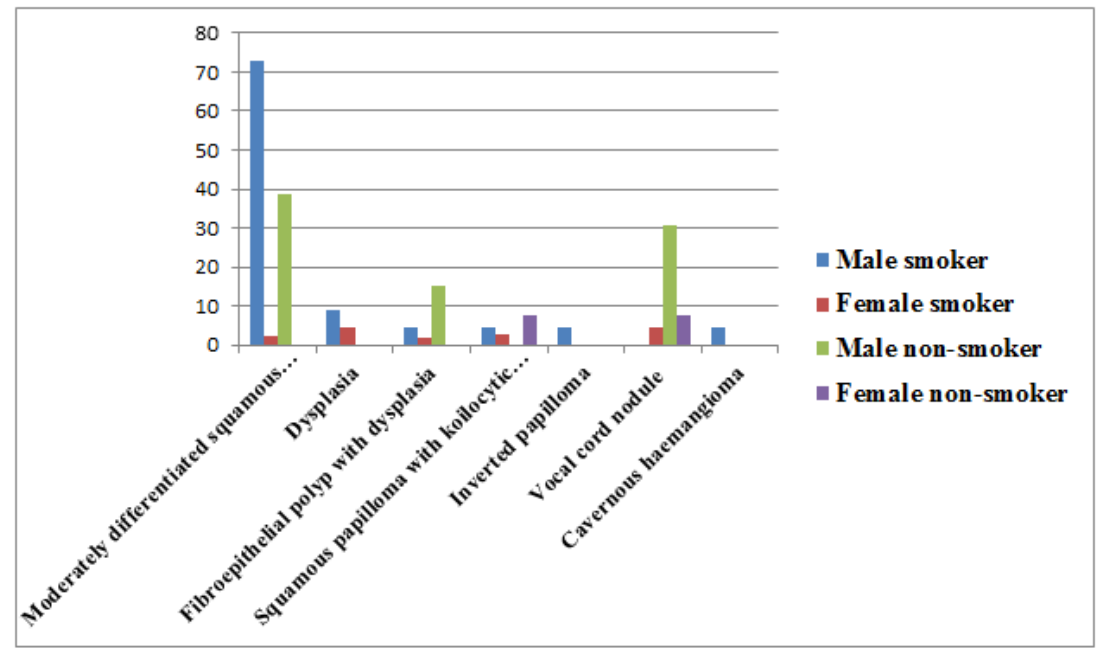

Graph-3(b): Distribution of sex with history of smoking among patients with laryngeal mass

Inference- $72.7 \%$ male smoker patients have moderately differentiated squamous cell carcinoma.

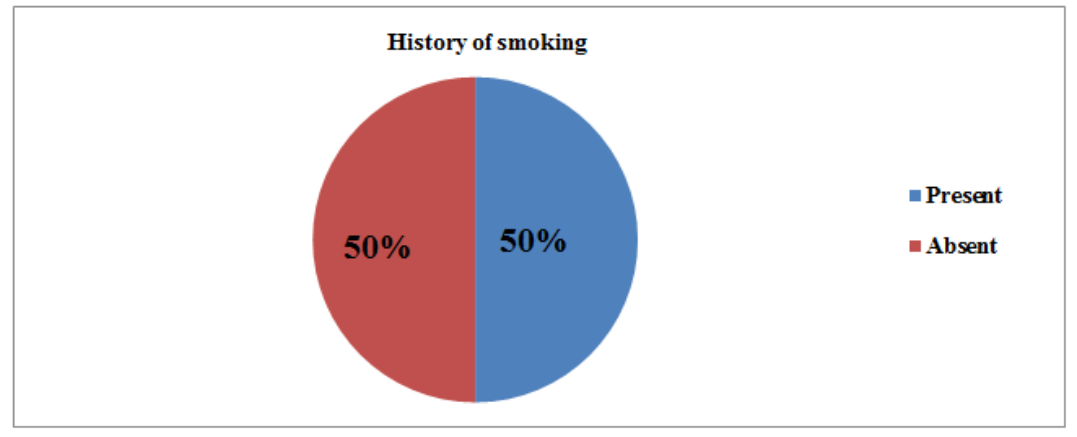

Graph-3(c): Distribution of sex with history of smoking among patients with nasopharyngeal mass

Inference- In the present study, 50\% patients with nasopharyngeal mass have positive history of smoking, whereas, another $50 \%$ patients have no history of smoking

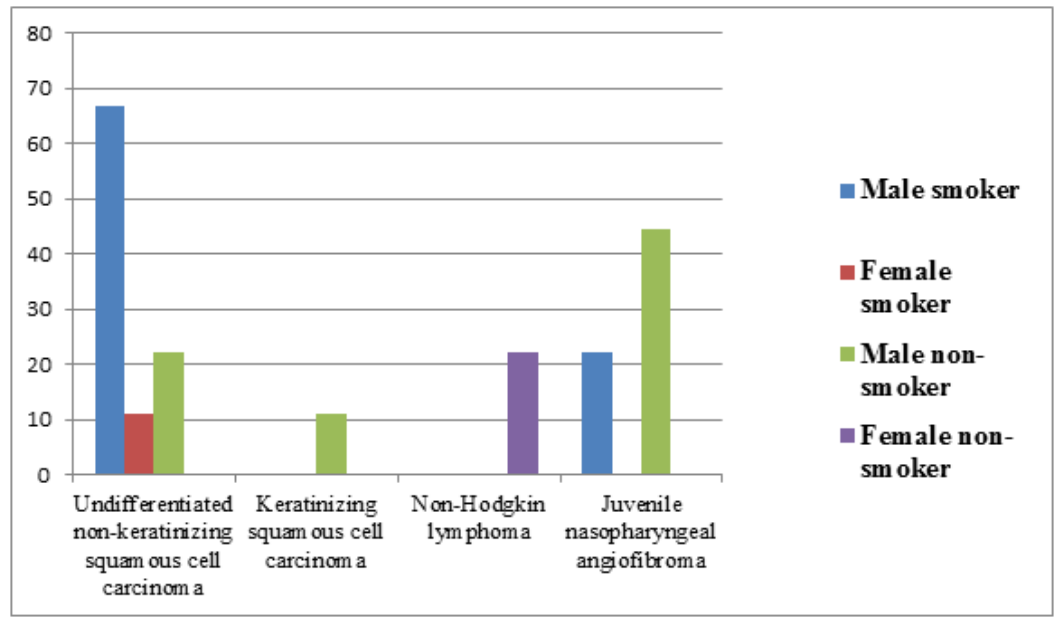

\section{Graph-3(d): Distribution of sex with history of smoking among patients with nasopharyngeal mass}

Inference- In this study, $66.7 \%$ male smoker patients have undifferentiated non-keratinizing squamous cell carcinoma and $44.44 \%$ male non-smoker patients have juvenile nasopharyngeal carcinoma. 


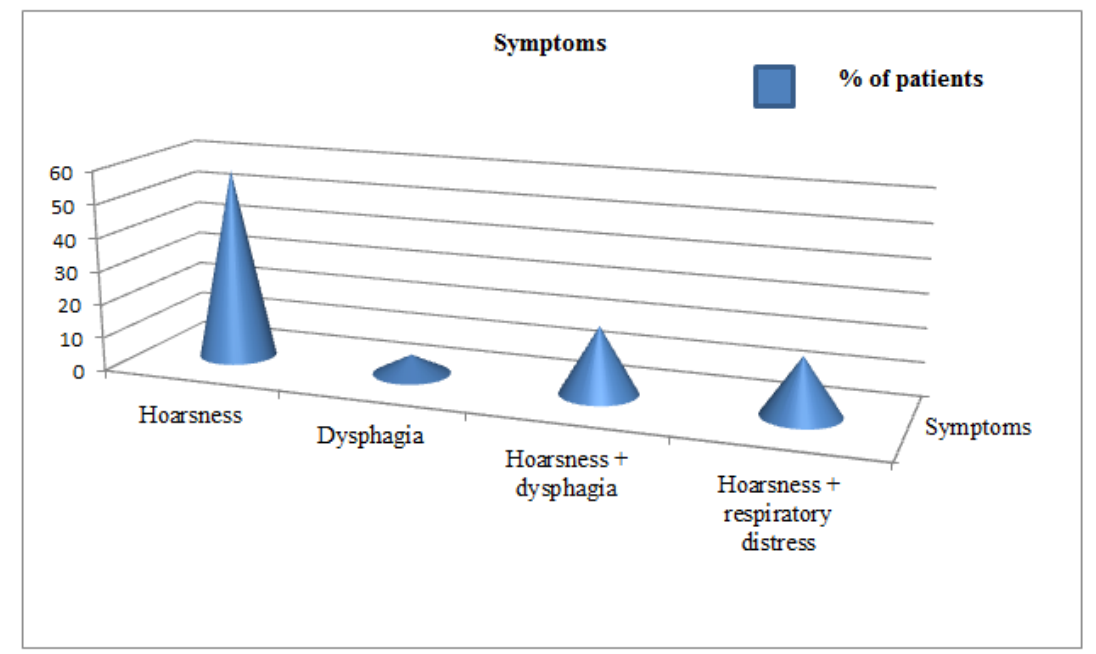

Graph-4(a): Distribution of symptoms among patients with laryngeal mass

Inference- Majority of patients with laryngeal mass was with the symptoms of hoarsness of voice.

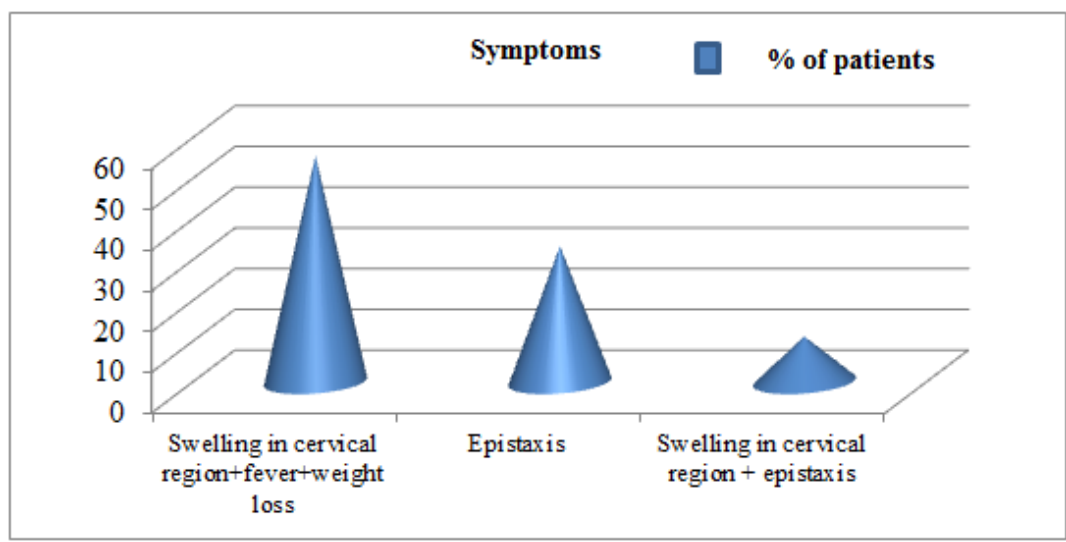

Graph-4(b): Distribution of symptoms among patients with nasopharyngeal mass

Inference- Majority of patients with nasopharyngeal mass was with the symptoms of swelling in cervical region, fever and weight loss.

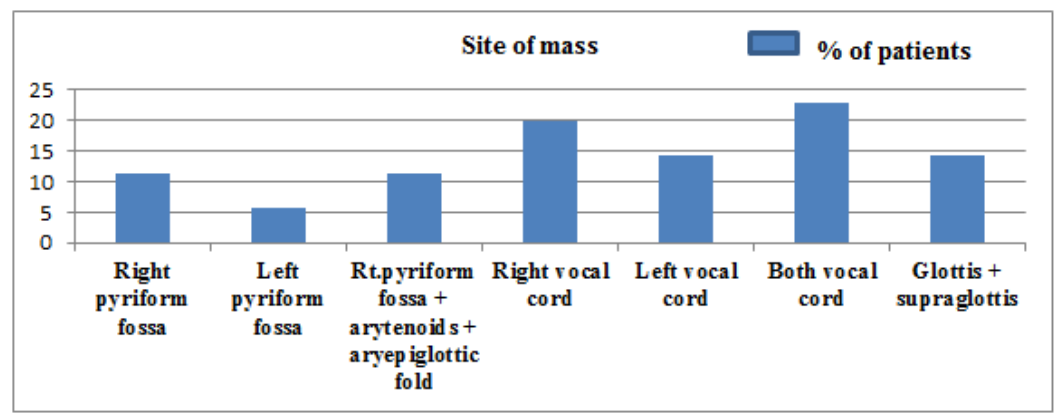

Graph-5: Distribution of site of mass by fibre optic laryngoscopic findings among patients with laryngeal mass

Inference- Majority of the laryngeal mass are located at vocal cord (22.86\%), follow by right vocal cord (20\%), left vocal cord (14.29\%) and glottis and supraglottis (14.29\%). 


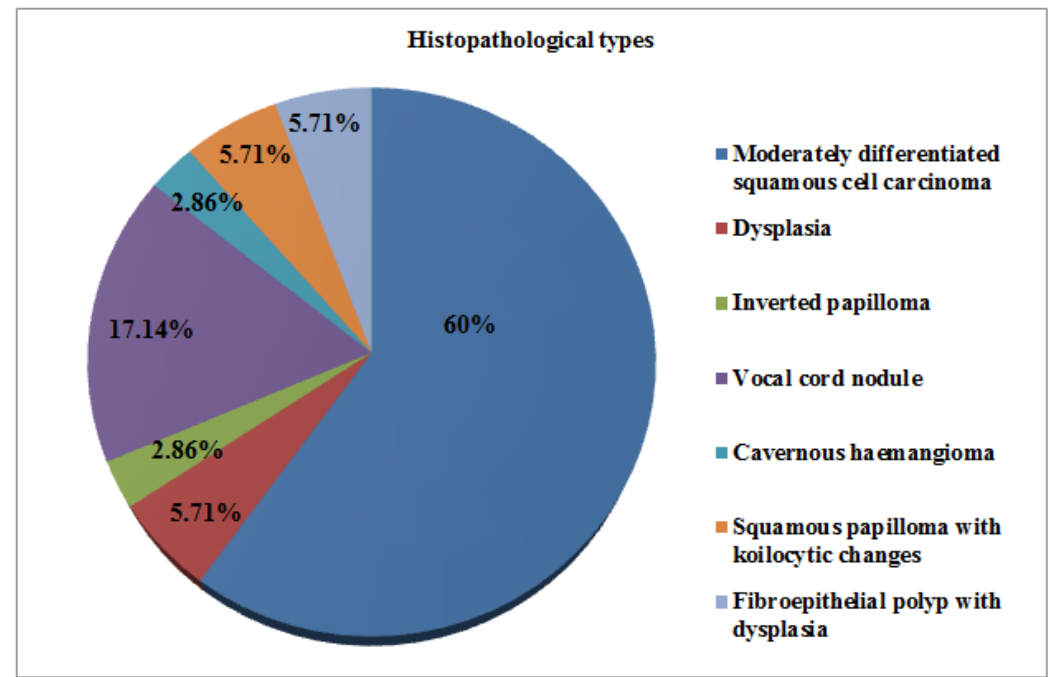

\section{Graph-6(a): Distribution of histopathological types among patients with laryngeal mass}

Inference- Majority of patients with laryngeal mass have moderately differentiated squamous cell carcinoma $(60 \%)$ followed by vocal cord nodule $(17.14 \%)$.

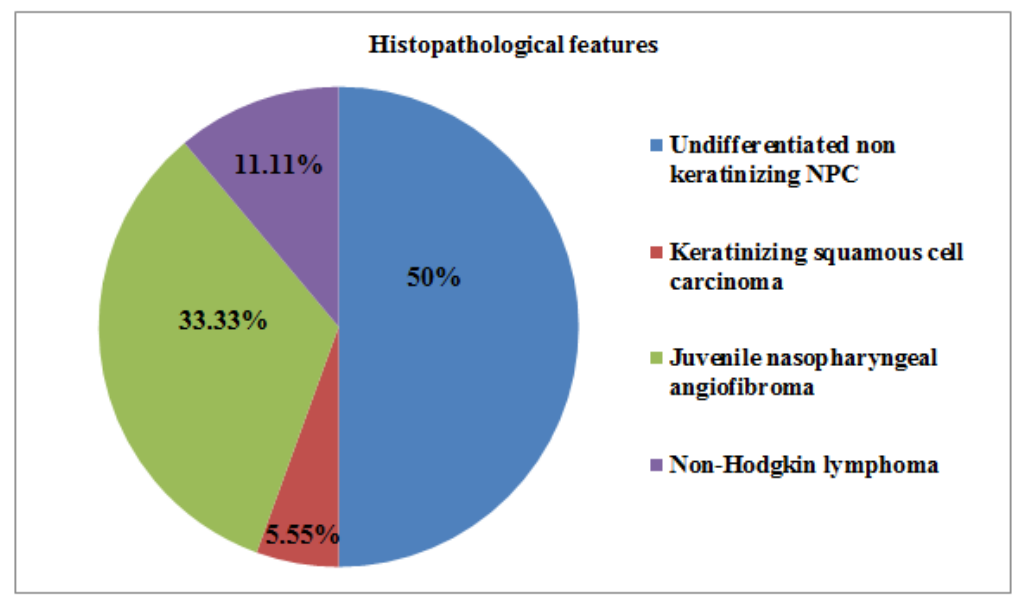

\section{Graph-6(b): Distribution of histopathological types among patients with nasopharyngeal mass}

Inference- Majority of patients with nasopharyngeal mass has undifferentiated non-keratinizing NPC (50\%), followed by juvenile nasopharyngeal angiofibroma (33.33\%).
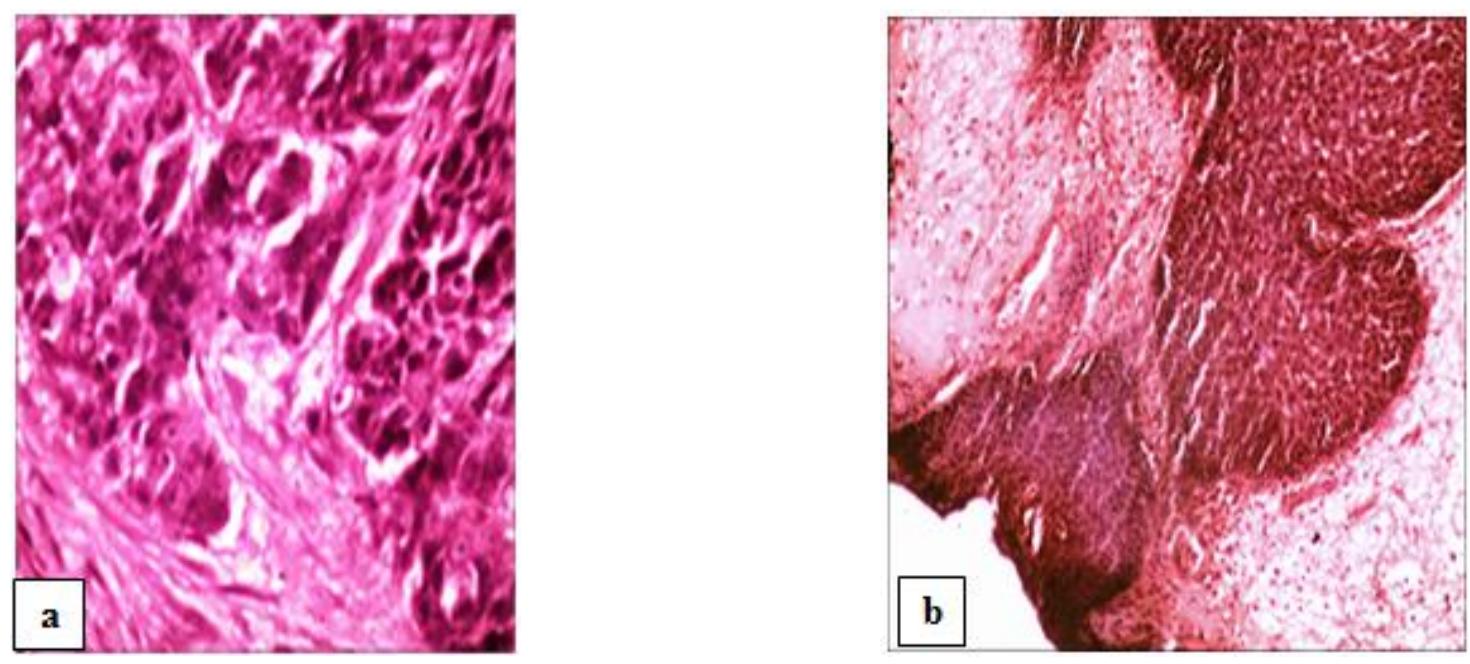

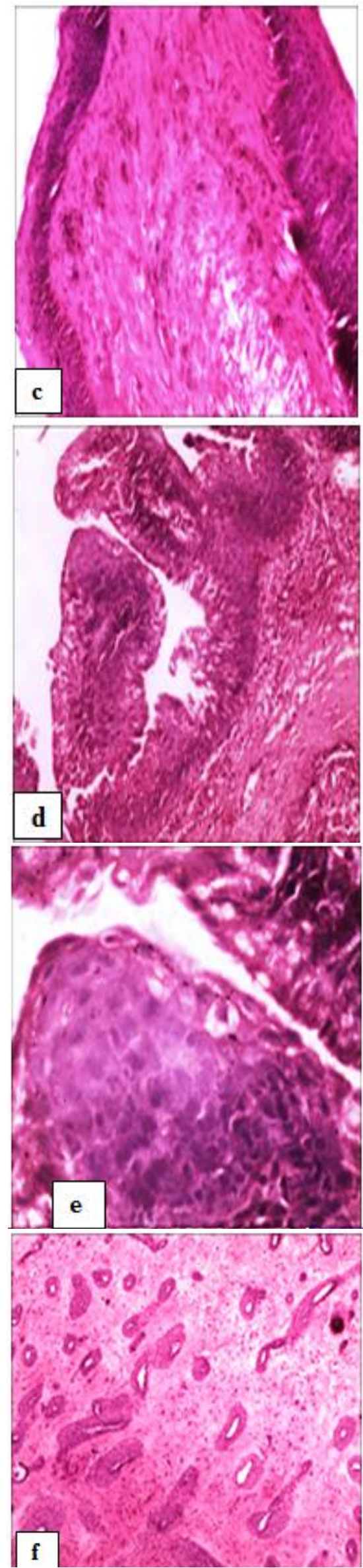

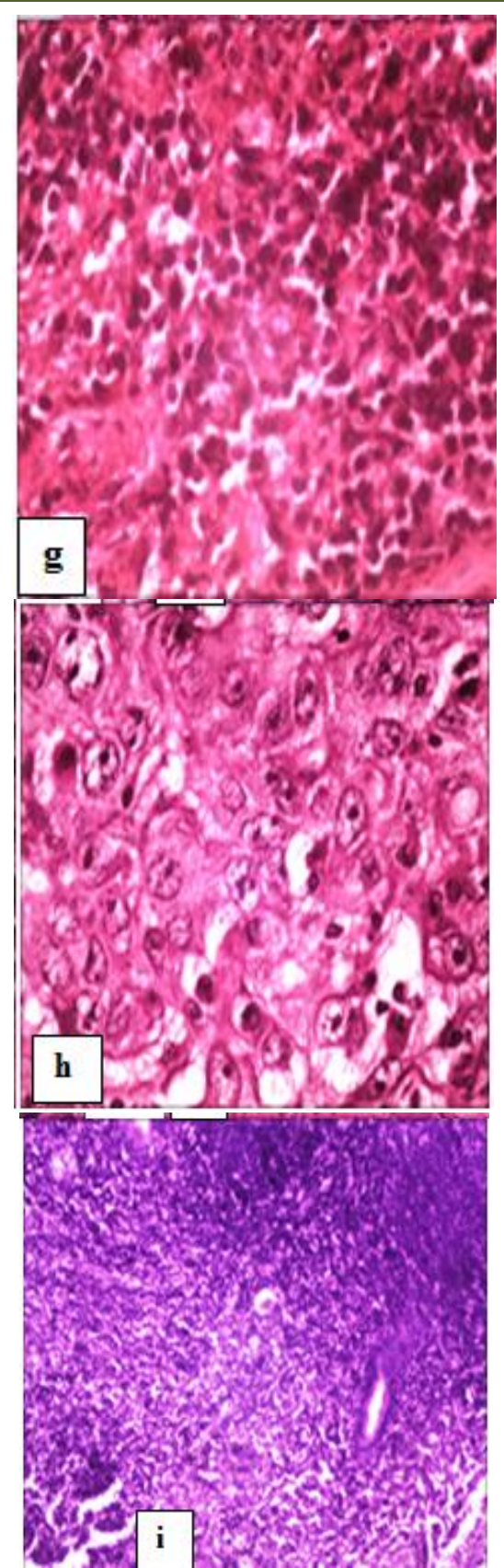

Photomicrograph : a) Moderately differentiated squamous cell carcinoma, H \& E stain (40X), b) Vocal cord nodule, H \& E stain (10X), c) Inverted papilloma, H\& E stain (10X), d) Squamous papilloma with koilocytic changes, $\mathrm{H} \& \mathrm{E}$ stain (10X), e) Squamous papilloma with koilocytic changes, H \& E stain (40X), f) Juvenile nasopharyngeal angiofibroma, $\mathrm{H} \& \mathrm{E}$ stain $(4 \mathrm{X}), \mathrm{g})$ Undifferentiated non-keratinizing nasopharyngeal squamous cell carcinoma, H \& E stain (40X), h) Undifferentiated nonkeratinizing nasopharyngeal squamous cell carcinoma, $\mathbf{H} \& \mathbf{E}$ stain (40X), i) Non-Hodgkin lymphoma of nasopharynx, H \& E stain (10X)

\section{DisCUSSION}

35 patients with laryngeal mass and 18 patients with nasopharyngeal mass are included in the study during the period of one and half year and history, clinical examination, histopathological examination and PCR were performed to ascertain the association of HPV-16, 18 with different histopathological types. 
In the present study of 35 patients with laryngeal mass, there are $32(91.4 \%)$ males and 3 $(8.6 \%)$ females and in patients with nasopharyngeal mass, there are $14(77.78 \%)$ males and $4(22.22 \%)$ female among 18 patients. Majority of patients with laryngeal mass $(40 \%)$ are in the 51 to 60years and nasopharyngeal mass are 11-20 years $(27.78 \%)$. A study by Nitin Arora et al. showed that laryngeal cancers were more common in males $(93 \%)$, than in female $(7 \%)$ and it is most prevalent in age group of 51 to 60 years (45\%) [16] A study conducted by Hannu S et al. with $302(95 \%)$ males and $16(5 \%)$ females showed that the mean age of men at the time of diagnosis was 62.8 years and that of women 60.8 years. Doloi, P.K. et al. [17] showed incidence of vocal cord nodule more in male with a male-to-female ratio 4:1. Xie SH et al. [18]; showed that the overall male to female ratio of the annual age-standardised incidence rates of nasopharyngeal carcinoma ranged 2.2-3.1. The male to female ratio of NPC incidence increased with age until peaking at ages 55-59 yearas and a decline thereafter [19]. A study by Coutinho-camillo CM et al. in juvenile nasopharyngeal angiofibroma showed that adolescents and young adults between 14 and 25 years are affected, and there is a distinct male predominance [20].

In this present study, $62.86 \%$ patient with laryngeal mass has history of smoking. Among them, $72.7 \%$ male smoker patients have moderately differentiated squamous cell carcinoma, 9.09\% male smokers have dysplalsia, $4.55 \%$ male smokers have squamous papilloma with koilocytic changes, $4.55 \%$ male smoker patients have inverted papilloma $4.55 \%$ female smokers have vocal cord nodule, $4.55 \%$ male smoker patients have cavernous haemangioma. But $38.5 \%$ non-smoker male also have moderately differentiated squamous cell carcinoma, $15.4 \%$ nonsmoker male have fibroepithelial polyp with dysplasia, $7.69 \%$ female nonsmoker patients have squamous papilloma with koilocytic changes, $30.8 \%$ nonsmoker male and $7.69 \%$ female nonsmoker have vocal cord nodule. National Cancer Registry Program enlists laryngeal cancer as one of the tobacco-related cancer. Rao et al. [21] found that biddi and cigarette smoking to be associated with cancer of the larynx[22]. Pyeko Menach et al. showed that $33(66 \%)$ of the experimental group patients had a positive history of current cigarette smoking compared to controls (6\%) and among patients who smoked and did not drink alcohol, 4(20\%) had glottic cancer $(\mathrm{p}=0.001)$ with an OR of 19.75, which was statistically significant [23]. A study by Silvano Gallus et al., based on the largest published dataset on laryngeal cancer in women, confirms that tobacco smoking is the most important risk for women as for men and tobacco appears to have a greater role in women than in men [24]. Drasko Cikojevic et al. showed that the proportion of smokers was lowest in benign lesion group $(72.13 \%$ ) and highest in malignant lesion group $(97.14 \%)$ and there was a statistically significant difference in the prevalence of smoking habit between patients with laryngeal tumours and those with benign or precancerous laryngeal lesion $(\mathrm{p}<0.001)[25]$.

In the present study, half of the study population with nasopharyngeal mass have a positive history of smoking and another half $(50 \%)$ have no history of smoking and $66.7 \%$ male smoker and $11.11 \%$ female smoker and $22.22 \%$ male nonsmoker patients have undifferentiated non keratinizing squamous cell carcinoma. $11.11 \%$ male nonsmoker has keratinizing squamous cell carcinoma and $22.22 \%$ female nonsmoker patient has non-Hodgkin lymphoma and $22.2 \%$ male smoker and $44.44 \%$ male nonsmoker patients have juvenile nasopharyngeal angiofibroma. A study by $\mathrm{M}$ Long et al. showed that significantly increased risk was only found among male smokers (OR 1.36), not among female smokers (OR 1.58) and significantly increased risk also existed in the differentiated (OR 2.34) and the undifferentiated type of NPC (OR 1.15)[26].

Common presenting symptoms in the present study in case of laryngeal mass are hoarsness in $57.14 \%$, followed by hoarsness and dysphagia in $20 \%$ patients, hoarsness and respiratory distress in $17.14 \%$ patients, only dysphagia in $5.71 \%$ patients and in cases of nasopharyngeal angiofibroma, majority of the patients $(55.56 \%)$ presented with swelling in cervical region, fever with weight loss, whereas, $33.33 \%$ patients have epitstaxis and $11.11 \%$ have swelling in cervical region and epistaxis. In 2016, Reddy DS et al. showed that out of 50 cases of benign lesions of larynx, $34(68 \%)$ were males and female were $16(32 \%)$ and all patients were presented with hoarsness of voice[27]. The symptoms of laryngeal cancer depend on the size and location of the tumour. Symptoms are-hoarsness or other voice changes, a lump in the neck, a sore throat or feeling that something stuck in the throat, persistent cough, stridor, bad breath, earache (referred), difficulty swallowing [28]. S. Marc Stokes et al. showed that nasopharyngeal angiofibroma presents as a nasal mass or obstruction o with repeated episodes of epistaxis [29]. Swelling of the lymph nodes in the neck is the initial presentation in many patients of nasopharyngeal carcinoma [30].

In this present study, most common site of laryngeal mass detected by fibre optic laryngoscopy is bilateral vocal cord $(22.86 \%)$, followed by right vocal cord (20\%), glottis and supraglottis (14.29\%) and left vocal cord (14.29\%), right pyriform fossa (11.43\%), right pyriform fossa with arytenoids and aryepiglottic fold $(11.43 \%)$. Most laryngeal cancers originate in the glottis (true vocal cords, anterior and posterior commissures). Supraglottic cancers (epiglottis, arytenoids and aryepiglottic folds, and false cords) are less common, and subglottic tumours are least frequent [31]. Ayotunde James Fasunla et al. showed that 
transglottis $(91.8 \%)$ was the most common anatomic tumor location [32]. Dinesh Kumar Sharma et al. showed that the majority of the benign tumours in the larynx arose from the glottic region $(70 \%)$ followed by that of supraglottic region $(25 \%)$ [33].

In this study, nasopharyngeal masses are detected by endoscopic biopsy and CECT Scan of head and neck and all the masses are located at fossa of Rossenmullar.

In this study, among the patients with laryngeal masses, $60 \%$ of them have moderately differentiated squamous cell carcinoma, $5.71 \%$ patients have dysplasia, $2.86 \%$ patients have inverted papilloma, $17.14 \%$ patients have vocal cord nodule, $2.86 \%$ patients with cavernous haemangioma, $5.71 \%$ patients have squamous papilloma with koilocytic changes and another $5.71 \%$ patients have fibro epithelial polyp with dysplasia. Similarly, Dinesh Kumar Sharma et al. showed that squamous cell carcinoma was the most common malignant tumour detected in the larynx and in cases of malignant tumours $100 \%$ were squamous cell carcinoma [33]. Manish Sharma et al. have showed in their study that $32 \%$ patients have vocal cord nodule and $2 \%$ have haemangioma[34]. Aniket R. Buche et al. showed that $45 \%$ cases have vocal cord nodule and $5 \%$ patients have laryngeal papillomatosis among the patients with benign lesions of larynx [35].

In this study, among the patients with nasopharyngeal mass $50 \%$ patients have undifferentiated non keratinizing squamous cell carcinoma, $5.55 \%$ have keratinizing squamous cell carcinoma, $11.11 \%$ patients have non-Hodgkin lymphoma and rest $33.33 \%$ patients have juvenile nasopharyngeal angiofibroma. Rudresha Antapura Haleshappa et al. showed that $84 \%$ cases had the WHO Type 3 histology while only $16 \%$ cases had the WHO Type 2 histology and none of the cases had welldifferentiated keratinizing squamous cell carcinoma. Common symptoms at presentation were neck swelling in $80 \%$ cases and nasal obstruction and/or epistaxis in $28 \%$ cases [36]. In this study, HPV-16, HPV-18 is not identified by conventional PCR method in any laryngeal or nasopharyngeal mass. A study by Ozlem Onerci Celebi et al. showed that HPV was not detected in any of the 82 laryngeal cancer patients' laryngeal specimens, nor in any of the 11 archieved laryngeal speciments with normal laryngeal mucosa via cISH.. Genotyping confirmed these findings; none of the HPV types studied were detected in any of the specimens. HPV infection is not a leading cause of laryngeal cancer [37]. Brenda Y. Hernandez et al. detect the presence of genotype-specific HPV DNA using the Linear Array HPV Genotyping test and the INNO-LiPA HPV genotyping assay in formalin -fixed paraffin embedded tissue from 148 invasive laryngeal cancers and HPV DNA was detected in 31 of $148(21 \%)$ invasive laryngeal cancer. Thirteen different genotypes were detected. Overall, HPV 16 and HPV 33 were the most commonly detected types [38] In their study, Davids T et al. identified the specimens having dysplasia and then these specimens were underwent further testing via in situ hybridization for low-risk (6/11) or high-risk (16/18) HPV subtypes. They showed that of the 85 subjects identified to have laryngeal papillomatosis, 24 $(28 \%)$ demonstrated laryngeal dysplasia, among these, the majority of patients $(62 \%)$ were positive for HPV $6 / 11$, including high grade dysplasia patients. Three (12\%) dysplasia specimens were negative for both highand low- risk HPV subtypes [39]. In their study, Max Robinson et al. detected high-risk HPV by screening all cases for p16 using immunohistochemistry and HPV DNA by PCR using GP5+/6+ primers and then all cases with p16 overexpression or positive for HPV by PCR were then examined by high-risk HPV DNA insitu hybridization and genotype analysis by PCR. Out of 67 cases, 11 cases $(16.4 \%)$ showed concurrent overexpression of p16 and evidence of high-risk DNA by in-situ hybridizsation; the majority were HPV 16 positive. Histologically, there were 2 keratinizing squamous cell carcinoma and 9 non-keratinizing carcinomas. None of the HPV positive cases showed any co-infection with EBV [40].

\section{CONCLUSION}

Though this study is too small to conclude, conventional PCR may not enough to diagnose HPV16,18 from tissue and HPV-16, 18 may not be a leading cause of laryngeal or nasopharyngeal mass.

\section{REFFERENCE}

1. Zeyi Deng. Epstein-Barr virus Infection and Genotypes in-Head and Neck Cancers; November, 2014;9(11):e113702

2. Walboomers. Human papilloma virus is a necessary cause of invasive cervical cancer worldwide. The Journal of Pathology. 1999; 189: 12-19.

3. Koskinen. Alcohol, smoking and human papilloma virus in laryngeal carcinoma: a Nordic prospective multicenter study. Journal of Cancer Research and Clinical oncology. 2007; 133: 673-678.

4. Bonagura VR, Hatam LJ, Rosenthal DW, De Voti JA, Lam F, Steinberg BM, Abramson AL. Recurrent respiratory papillomatosis: a complex defect in immune responsiveness to human papillomavirus-6 and-11. Apmis. 2010 Jun;118(67):455-70.

5. Lee SY, Cho NH, Choi EC, Kim WS, Kim SH. Is human papillomavirus a causative factor of glottic cancer?. Journal of Voice. 2011 Nov 1;25(6):770-4.

6. Upile NS, Shaw RJ, Jones TM, Goodyear P, Liloglou T, Risk JM, Boyd MT, Sheard J, Sloan P, Robinson M, Schache AG. Squamous cell carcinoma of the head and neck outside the oropharynx is rarely human papillomavirus related. The Laryngoscope. 2014 Dec;124(12):2739-44. 
7. Xu Y, Liu S, Yi H, Wang J, Dong P, Li X, Yin S. Human papillomavirus infection in 674 Chinese patients with laryngeal squamous cell carcinoma. PLoS One. 2014;9(12).

8. Agalliu I, Gapstur S, Chen Z, Wang T, Anderson RL, Teras L, Kreimer AR, Hayes RB, Freedman ND, Burk RD. Associations of oral $\alpha-, \beta$-, and $\gamma$ human papillomavirus types with risk of incident head and neck cancer. JAMA oncology. 2016 May 1;2(5):599-606.

9. D'Souza G, Kreimer AR, Viscidi R, Pawlita M, Fakhry C, Koch WM, Westra WH, Gillison ML. Case-control study of human papillomavirus and oropharyngeal cancer. New England Journal of Medicine. 2007 May 10;356(19):1944-56.

10. Snow AN, Laudadio J. Human papillomavirus detection in head and neck squamous cell carcinomas. Advances in anatomic pathology. 2010 Nov 1;17(6):394-403.

11. Chen X, Gao L, Sturgis EM, Liang Z, Zhu Y, Xia X, Zhu X, Chen X, Li G, Gao Z. HPV16 DNA and integration in normal and malignant epithelium: implications for the etiology of laryngeal squamous cell carcinoma. Annals of Oncology. 2017 May 1;28(5):1105-10.

12. Gillison ML, Koch WM, Capone RB, Spafford M, Westra WH, Wu L, Zahurak ML, Daniel RW, Viglione M, Symer DE, Shah KV. Evidence for a causal association between human papillomavirus and a subset of head and neck cancers. Journal of the National Cancer Institute. 2000 May 3;92(9):709-20.

13. Ang KK, Harris J, Wheeler R, Weber R, Rosenthal DI, Nguyen-Tân PF, Westra WH, Chung CH, Jordan RC, Lu C, Kim H. Human papillomavirus and survival of patients with oropharyngeal cancer. New England Journal of Medicine. $2010 \mathrm{Jul}$ 1;363(1):24-35.

14. Gullane PJ, Davidson J, O'Dwyer T, Forte V. Juvenile angiofibroma: a review of the literature and a case series report. The Laryngoscope. 1992 Aug;102(8):928-33.

15. Mishra A, Sachadeva M, Jain A, Shukla NM, Pandey A. Human papilloma virus in juvenile nasopharyngeal angiofibroma: possible recent trend. American journal of otolaryngology. 2016 Jul 1;37(4):317-22.

16. Arora N, Singh J, Davessar JL. Epidemiological Profile of Larynx Cancer at a Tertiary Care Center in Faridkot, Punjab, India. Int $\mathbf{J}$ Phonosurg Laryngol. 2017;7(2):48-51.

17. Raitiola HS, Pukander JS. Changing trends in the incidence of laryngeal cancer. Acta Oncologica. 1997 Jan 1;36(1):33-6.

18. Doloi PK, Khanna S. A study of management of benign lesions of the larynx. IJOPL. 2011 Jul;1(2):61-4.

19. Xie SH, Yu IT, Tse LA, Mang OW, Yue L. Sex difference in the incidence of nasopharyngeal carcinoma in Hong Kong 1983-2008: suggestion of a potential protective role of oestrogen. European Journal of Cancer. 2013 Jan 1;49(1):1505 .

20. Coutinho-Camillo CM, Brentani MM, Nagai MA. Genetic alterations in juvenile nasopharyngeal angiofibromas. Head \& Neck: Journal for the Sciences and Specialties of the Head and Neck. 2008 Mar;30(3):390-400.

21. Three-year Report of Population Based Cancer Registries 2009-2011. Ch. 3. Bangalore: National Cancer Registry Program (ICMR); 2013. ICMR. Sites of cancer associated with use of tobacco. 2013: 23-6.

22. Rao DN, Desai PB, Ganesh B. Alcohol as an additional risk factor in laryngopharyngeal cancer in Mumbai - A case-control study. Cancer Detect Prev. 1999;23:37-44

23. Pyeko Menach, Herbert O. Oburra, Asmeeta Patel: Cigarette Smoking and Alcohol Ingestion as Risk Factors for Laryngeal Squamous Cell Carcinoma at Kenyatta National Hospital, Kenya. Clin Med Insights Ear Nose Throat. 2012;5:17-24

24. Gallus S, Bosetti C, Franceschi S, Levi F, Negri E, La Vecchia C. Laryngeal cancer in women: tobacco, alcohol, nutritional, and hormonal factors. Cancer Epidemiology and Prevention Biomarkers. 2003 Jun 1;12(6):514-7.

25. Cikojević D, Glunčić I, Klančnik M. Cigarette smoking and progression of laryngeal lesions. Collegium antropologicum. 2010 Mar 25;34(1):458.

26. Long M, Fu Z, Li P, Nie Z. Cigarette smoking and the risk of nasopharyngeal carcinoma: a metaanalysis of epidemiological studies. BMJ open. 2017 Oct 1;7(10):e016582.

27. Reddy DS, Rathod JB, Dham R, Babu AS, Nagaraj K, Srinivas K, Kumuda C, Reddy BS. Benign lesions of larynx: a clinical study of 50 cases. J Evid Based Med Healthc. 2016;3(2):72-7.

28. DeVita, Hellman, and Rosenberg's Cancer: Principles \& Practice of Oncology $10^{\text {th }}$ edition.

29. Stokes SM, Castle JT. Nasopharyngeal angiofibroma of the nasal cavity. Head and neck pathology. 2010 Sep 1;4(3):210-3.

30. Nasopharynx cancer- Wikipedia

31. Laryngeal cancer-Wikipedia

32. Fasunla AJ, Ogundoyin OA, Onakoya PA, Nwaorgu OG. Malignant tumors of the larynx: Clinicopathologic profile and implication for late disease presentation. Nigerian medical journal: journal of the Nigeria Medical Association. 2016 Sep;57(5):280.

33. Sharma DK, Sohal BS, Bal MS, Aggarwal S. Clinico-pathological study of 50 cases of tumours of larynx. Indian Journal of Otolaryngology and Head \& Neck Surgery. 2013 Jul 1;65(1):29-35.

34. Sharma M, Kumar S, Goel M, Angral S, Kapoor M. A clinical study of benign lesions of larynx. International Journal of Oral Health and Medical Research. 2015;2(2):22-8. 
35. Buche AR, Garud SH, Jaiswal SA, Chamania GA. Benign lesions of laryn $-\mathrm{a}$ clinicopathological study. IOSR J Dent Med Sci. 2016;15:09-17.

36. Haleshappa RA, Thanky AH, Kuntegowdanahalli L, Kanakasetty GB, Dasappa L, Jacob L. Epidemiology and outcomes of nasopharyngeal carcinoma: Experience from a regional cancer center in Southern India. South Asian journal of cancer. 2017 Jul;6(3):122.

37. Celebi OO, Sener E, Hosal S, Cengiz M, Gullu I, Tezel GG. Human papillomavirus infection in patients with laryngeal carcinoma. BMC cancer. 2018 Dec 1;18(1):1005.

38. Hernandez BY, Goodman MT, Lynch CF, Cozen W, Unger ER, Steinau M, Thompson T, Saber MS,
Altekruse SF, Lyu C, Saraiya M. Human papillomavirus prevalence in invasive laryngeal cancer in the United States. PloS one. 2014;9(12).

39. Davids T, Muller S, Wise JC, Johns III MM, Klein A. Laryngeal papillomatosis associated dysplasia in the adult population: an update on prevalence and HPV subtyping. Annals of Otology, Rhinology \& Laryngology. 2014 Jun;123(6):402-8.

40. Robinson M, Suh YE, Paleri V, Devlin D, Ayaz B, Pertl L, Thavaraj S. Oncogenic human papillomavirus-associated nasopharyngeal carcinoma: an observational study of correlation with ethnicity, histological subtype and outcome in a UK population. Infectious agents and cancer. 2013 Dec 1;8(1):30. 